\title{
Prospects for global health: lessons from tuberculosis
}

The primary aim of medicine is to enhance the quality of life and promote the health of mankind. Despite almost undreamed of medical progress over many decades, especially in developed countries, preventable diseases still blight the lives of billions worldwide in both rich and poor nations. The success of the World Health Organisation's programme for the worldwide elimination of smallpox exemplifies what can be achieved in our modern scientific world. Control of other diseases will be more difficult and require greater international collaboration. Societal and professional apathy to human suffering at the population level, and the paucity of coordinated international endeavours to address global health issues, are increasingly being confronted and debated. "Health for all by 2000 " or beyond - is, however, a meaningless slogan in the absence of a paradigm shift in thinking about global health. ${ }^{1}$ Tuberculosis, an old disease again in the limelight, provides an opportunity to confront the challenge.

In the 113 years since Koch discovered Mycobacterium tuberculosis impressive advances have been made in our scientific knowledge of this organism, the disorders it produces in man, and its medical treatment and cure. New diagnostic techniques (including sophisticated molecular biology procedures), development of a range of therapeutic drugs with deeper understanding of their mode of action, modern drug regimens based on superbly designed and conducted trials, application of social science methodology to understanding patient perceptions of disease and to improving compliance have all contributed to a biopsychosocial understanding of the disease which contains all the ingredients for the successful control of tuberculosis, at least at the national level..$^{2-4}$

Despite these impressive scientific advances, tuberculosis constitutes a growing and even more threatening problem worldwide. ${ }^{56}$ Given the estimate that one third of the world's population is infected with $M$ tuberculosis, the recognition that HIV infection is increasing the proportion of those in whom infection will progress to tuberculous disease, that HIV and $M$ tuberculosis infections co-exist most extensively in the poorest parts of the world, the inadequacy of tuberculosis control programmes, the development of multidrug resistance, and the ease with which infections are transmitted across the modern world, necessary scientific progress and humanitarian aid to developing countries may be not sufficient to avert the potential tragedy of untreatable tuberculosis. ${ }^{4-8}$

This paradox between the success of creative scientific endeavours to cure and control a pandemic infectious disease and consequent potential failure in this quest provides an opportunity for some reflection on the past, to contextualise a perspective of the present and a vision

Table 1 Population statistics for some more developed and less developed countries (mid 1990s). (Data compiled from ref 10)

\begin{tabular}{lcc}
\hline & $\begin{array}{c}\text { More developed } \\
\text { countries }\end{array}$ & $\begin{array}{l}\text { Less well developed } \\
\text { countries }\end{array}$ \\
\hline Population (million) & 1214 & 4107 \\
Urbanised (\%) & 73 & 32 \\
Death rate* & 9 & 10 \\
Birth rate* & 15 & 31 \\
Infant mortality rate & 16 & 81 \\
Natural annual increase (\%) & $0 \cdot 5$ & $2 \cdot 1$ \\
Population doubling time (years) & 128 & 33 \\
Per capita GNP (US\$) & 15830 & 710 \\
\hline
\end{tabular}

* Per 1000 popularion. of future requirements that could improve the health of individuals and populations.

\section{The past}

At the turn of the 19th century when the first tuberculosis epidemic was reaching its peak in western Europe, the Industrial Revolution was well under way leading to rapid population growth, and Britain was colonising India. In 1882 Koch identified $M$ tuberculosis and the next wave of the epidemic was reaching its peak in eastern Europe while major European nations were either at war or planning the colonisation of Africa (following the Berlin Conference of 1885). When tuberculosis peaked in India and China at the beginning of the 20th century, world population had increased to almost two billion. The crest of the next wave reached subSaharan Africa in the mid 20th century when the world population was four billion and the colonising powers were retreating from an era in Africa that would impact deeply into the future of the continent.

The demographic transition and stabilisation of population growth typical of countries industrialising during the late 19th and early 20th centuries in Europe and North America has not been repeated in other countries. The social, economic and political events associated with colonialism and other imperialistic forces resulted in a declining death rate without the concomitant industrialisation, education, improvement in living conditions, and fall in birth rate that were central features of the demographic transition in Europe and America (and which resulted in a progressive fall in mortality from tuberculosis and other infectious diseases). This, together with other destabilising effects of independence under adverse conditions (including the effects of neocolonialism, corruption, being used as "pawns" in the cold war, drought, famine, disease epidemics - including HIV infection - and against this background, genocidal tribal conflict) set many developing countries adrift from the industrialised world ${ }^{9-19}$ (table 1). It is in this context that the failure of Africa (and other developing countries) to replicate the demographic transition of developed countries must be $\operatorname{seen}^{18}$ (table 2). The global implications and very complex challenges posed by relentless population growth and the widening economic gap are increasingly being acknowledged and addressed..$^{9-21}$ The desperate plight of Africa, the continent most adversely affected by these historical developments, has recently been reviewed. ${ }^{16-18}$

\section{The present}

At the close of the 20th century the world's population will be almost six billion with predicted growth towards at least 11 billion by 2100 -a Malthusian problem in response to which some may see AIDS and tuberculosis (together with drought, famine, and conflict) as inevitable outcomes, while others retain faith in solutions from scientific advances $^{22}$ and humanitarian aid. ${ }^{6}$ The recent recrudescence of tuberculosis even in wealthy countries, despite scientific advances, reveals the shortcomings of relying on such advances alone in the absence of attention to the sociopolitical contexts in which health and disease are embedded. Pathways of economic, political and social development, initiated and sustained over many centuries, have carried us into a polarised, conflict-ridden, progressively dichotomised world. ${ }^{91121415}$ The peoples of all 
Table 2 World population distribution, growth rates and projected to 2100. (Data compiled from ref 10)

\begin{tabular}{|c|c|c|c|c|c|}
\hline & $1800(\%)$ & $1900(\%)$ & $2000(\%)$ & $2100(\%)$ & Growth rate (1990) (\%) \\
\hline Africa* & \multirow{7}{*}{$\begin{array}{c}10 \cdot 9 \\
64 \cdot 7 \\
21 \cdot 0 \\
2 \cdot 5 \\
0 \cdot 2 \\
0 \cdot 7 \\
\pm 100 \\
(1 \text { billion }) \\
3\end{array}$} & 9 & $13 \cdot 9$ & $26 \cdot 1$ & $2 \cdot 9$ \\
\hline Asia* & & $54 \cdot 6$ & $59 \cdot 2$ & $55 \cdot 5$ & 1.9 \\
\hline Europe/USSR & & $26 \cdot 9$ & $13 \cdot 1$ & $7 \cdot 4$ & $0 \cdot 3 / 0 \cdot 9$ \\
\hline Oceania & & $0 \cdot 4$ & 0.5 & 0.4 & $1 \cdot 2$ \\
\hline US/Canada & & $5 \cdot 2$ & $4 \cdot 7$ & $2 \cdot 9$ & $0 \cdot 7$ \\
\hline Total & & \pm 100 & \pm 100 & \pm 100 & $1 \cdot 8$ \\
\hline Urban \% & & 14 & $\begin{array}{l}41 \\
(1990)\end{array}$ & (11 Dillon) & \\
\hline
\end{tabular}

* Developing world: $77 \%$ of total in $1990,88 \%$ of total projected in 2100 .

nations are consequently threatened individually and collectively, albeit in different ways and with varying short term implications. ${ }^{9-21}$

These macro problems are of increasing concern to scientists, social scientists, philosophers, theologians and secular humanists, but seem to have impacted insufficiently on the minds of health professionals, beset as we are with so many other problems at the micro level of health care of individuals and meso level of health care delivery systems. A brief review of tuberculosis control at the global level is offered in the hope that this may help to broaden debate and understanding beyond easily recognised causal factors. Deeper and less openly acknowledged historical developments merit attention, and imaginative new approaches are needed that could influence the structure of health care systems and sustainable development programmes worldwide.

The global toll of tuberculosis and its epidemiological pattern have recently been reviewed. ${ }^{57}$ Each year eight million people develop tuberculous disease and almost three million die of tuberculosis, over $95 \%$ of these in developing countries. One billion people have died from tuberculosis in the 19th and 20th centuries, and 1.3 million cases and 450000 deaths from tuberculosis occur annually in those under the age of 15 years in developing countries worldwide. In 1990 there were 1.9 million deaths of patients over the age of five from tuberculosis compared with $1 \cdot 1$ million deaths from leprosy, malaria, tropical diseases, AIDS and diarrhoea combined. ${ }^{6}$

Fewer than 15 countries have a regular monitoring system to record cure rates, death rates and compliance rates, and it is estimated that the coverage of tuberculosis treatment services in $1988-9$ was $24 \%$ in Africa, $42 \%$ in the Americas (excluding USA and Canada), $44 \%$ in southeast Asia, $70 \%$ in the eastern Mediterranean, and $88 \%$ in the western Pacific (excluding China, Japan, and New Zealand).

In many developing countries fewer than $50 \%$ of patients who start treatment are cured or complete their course of treatment. The implications of such inadequate treatment for the control of tuberculosis and for development of resistant strains is becoming well known. ${ }^{223}$ The amplification effect of the HIV epidemic is already apparent and the World Health Organisation estimates that 3-4.5 million persons are dually infected with $M$ tuberculosis and HIV, many of whom live in subSaharan Africa. ${ }^{8}$

Since the first chemotherapeutic drug was introduced in 1944 only a few highly effective antituberculosis drugs have been developed. Although the therapy of tuberculosis has been placed on a sound scientific footing during the past 50 years, ${ }^{2425}$ inadequate implementation of control programmes has led to the emerging spectre of widespread multidrug resistance. ${ }^{6223}$ The treatment of patients so infected has become difficult because few highly effective new drugs are available, and drugs such as the quinolones are prohibitively expensive for all except the most wealthy nations. ${ }^{623}$
These developments vividly demonstrate the need for scientific advances (hopefully including immunotherapy $\vec{\circ}$ that could shorten the duration of drug treatment ${ }^{26}$ ) with potential for improving the cure of individuals to be incorporated into sound health care systems and linked to $\vec{x}$ other components of human development, if success in $\dot{0}$ treating individuals is to be transformed into improved of population health.

\section{The future}

In considering prospects for the improvement of health at a global level a major concern is to implement successful programmes for reducing population growth. To limit the world's population to 10 billion by the year 2100 will necessitate that all the world's couples of reproductive age have access to reliable, affordable contraceptives. ${ }^{10}$ Currently at $50 \%$, it is realistic to aim for $75 \%$ coverage by 2000 . If this can be achieved, family size will fall to about two children per couple within approximately 15 years.

Reaching the recommended contraceptive level will require a threefold increase in expenditure on contraceptives. To achieve this would require industrialised countries to increase their annual contribution to international population control efforts from an estimated US $\$ 534$ million in 1980 to US $\$ 4$ billion in 2000 . There is, however, no $\frac{0}{3}$ simple solution to the problem of uncontrolled population growth as this is but one manifestation of profound "system changes" in the varied processes of human development around the world. Modifying population growth can only be successfully addressed via a "systems approach" which $\frac{D}{O}$ takes into account many complex and interacting facets of development, including female literacy and empowerment, $\widetilde{\sigma}$ educational and job opportunities, improved living con- $N$ ditions, and prospects of longevity. A credible population N control programme must be linked to broader endeavours to narrow the economic gap between nations and in this way foster greater global stability. ${ }^{9227}$

A second major need, therefore, is for a new world $\stackrel{\mathscr{D}}{?}$ economic order which features linkage of financial aid to $T$ sustainable human development, rather than merely to consumption with its transient humanitarian effects. ${ }^{91227}$ This is a crucial and urgent challenge and a unifying $\unrhd$ concern for both developing and industrialised countries if social justice and the possibility of peace are to be $\delta$ achieved at a global level. In response to those who question the availability of resources for such action, attention must be drawn to how much official international aid has been inefficiently used over many decades, ${ }^{28}$ to the vast resources available if military expenditure can be reduced, ${ }^{13}$ and to the potential for extending the impact of available resources through more efficient use. It has been estimated that if only one third of the financial aid being used today was directed to human priority areas, the amount available for such use would increase fourfold. ${ }^{9}$ Examination of the activities of international drug companies also reveals the 
potential for corrective measures that could increase affordable access to drugs. ${ }^{29}$ Sustainable human development also needs to be linked to sustainable use of the environment - a challenge increasingly being recognised and addressed. ${ }^{91927}$

Finally, as we approach the 21 st century and face challenges of global magnitude, national pride and cultural hegemony must begin to accede to the call for a deeper understanding of our common humanity and its expression through tangible solidarity with the weak, underdeveloped people of the world. It is clear that the causes of tuberculosis, like AIDS and, indeed, many other diseases, are deeply rooted in social contexts and development patterns. ${ }^{19-213031}$ The problem and threat of multidrugresistant tuberculosis within a wealthy country such as the USA reflects in microcosm, within one nation, the limitations of "reductionist" approaches to "system" derangements which threaten health. Local and specific attempts at disease control can only be partially successful and must be coupled to acknowledgement of more profound causes and attempts to address some of the macro issues facing global human progress. Without this the selfinterest of developed nations will increasingly be threatened from within by poverty and diseases of poverty, and from without by a constant flow of refugees from the unchecked consequences of the fatal flaw of human development (overpopulation) in impoverished, conflict-ridden societies. ${ }^{112031}$

Progress towards a more stable world, capable of sustaining all its inhabitants under conditions of living and health that reflect the transformation of humanitarian concerns into a human and humane existence for all, is the profound challenge for the 21 st century.

Department of Medicine,

University of Cape Town

and Groote Schuur Hospital,

Observatory 7925,

Cape, South Africa
1 Lanza R, ed. Medical science and the advancement of world health. New York: Praeger, 1985.

2 Coovadia HM, Benatar SR, eds. A century of tuberculosis: South African perspectives. Cape Town: Oxford University Press, 1991.

3 Porter JDF, McAdam KPWJ, eds. Tuberculosis: back to the future. Chichester, UK: John Wiley, 1994.

4 Ryan F. Tuberculosis: the greatest story never told. Bromsgrove, UK: Swift, 1992.

5 Kochi A. The global tuberculosis situation and the new control strategy of the World Health Organisation. Tubercle 1991;72:1-6.

6 Kochi A. Tuberculosis: a global emergency. Geneva: WHO, 1994.

7 Grzybowski S. Tuberculosis in the third world. Thorax 1991;46:689-91.

8 De Cock KM, Soro B, Coulibaly IM, Lucas SB. Tuberculosis and HIV infection in sub-Saharan Africa. $\mathcal{F} A M A$ 1992;268:1581-7.

9 Human development report. United Nations Development Programme. New York: Oxford University Press, 1991.

10 World population: fundamentals of growth (student casebook), 2nd edn. Washington DC: Population Reference Bureau, 1990.

11 Kennedy P. Preparing for the twenty-first century. New York: Random House, 1993.

12 Investing in health. A World Bank Report, 1993.

13 Kiefer CW. Militarism and world health. Soc Sci Med 1992;34:719-24.

14 Gilbert A. An unequal world: the links between rich and poor nations. 2nd edn. Nelson, 1992.

15 Cahill K, ed. Health, human rights and humanitarian assistance in conflicts and disasters. New York: Basic Books, 1993.

16 Elmore-Meegan M, O'Riordan T. Africa on the precipice: an ominous but not yet hopeless future. $\mathcal{F} A M A 1993 ; 270 ; 629-31$.

17 Benatar SR. Africa and the world. S Afr Med F 1994;84:724-6.

18 Weiskel TC. Vicious circles: African demographic history as a warning. Harvard International Review 1994;Fall:12-6.

19 Ray JL. Global politics. 4th edn. Boston: Houghton-Miflin, 1992.

20 Potter VR. Getting to the year 3000: can global bioethics overcome evolution's fatal flaw. Global Bioethics 1990;34:89-98.

21 Hosle V. The third world as a philosophical problem. Social Res 1992;59. 227-62.

22 Spratt BG. Re-emergence of the captain of the men of death. Current Biol 1992;2:533-5.

23 Iseman MD. Treatment of multidrug-resistant tuberculosis. $N$ Engl f Med 1993;329:784-91.

24 Benatar SR. The evolution of anti-tuberculosis chemotherapy. In: Coovadia HM, Benatar SR, eds. A century of tuberculosis. Cape Town: Oxford University Press, 1991:258-70.

25 Ehlers MRW. The wolf at the door: some thoughts on the biochemistry of the tubercle bacillus. $S$ Afr Med $\mathscr{f}$ 1993;83:900-3.

26 Stanford JL, Grange JM. The promise of immunotherapy for tuberculosis. Respir Med 1994;88:3-7.

27 Butler C. Overpopulation, overconsumption and economics. Lancet 1994; 343:582-4.

28 Hancock G. Lords of poverty: the power, prestige and corruption of the international aid business. Boston: Atlantic Monthly Press, 1989.

29 Chetley A. A health business? World health and the pharmaceutical industry. London: Zed Books, 1990.

30 Sagan LA. The health of nations: true causes of sickness and well being. New York: Basic Books, 1987.

31 Toole MJ, Waldman RJ. Refugees and displaced persons; war, hunger and public health. $\mathscr{f} A M A 1993 ; 270: 600-5$. 